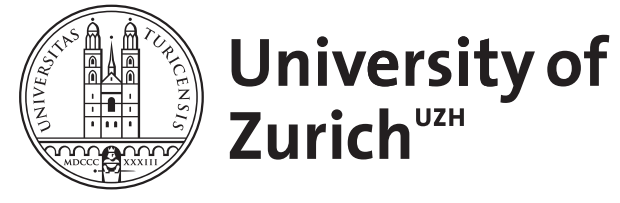

Zurich Open Repository and Archive

University of Zurich

University Library

Strickhofstrasse 39

CH-8057 Zurich

www.zora.uzh.ch

Year: 2012

\title{
Are multinational teams more successful?
}

Nüesch, Stephan

DOI: https://doi.org/10.1080/09585192.2011.610948

Posted at the Zurich Open Repository and Archive, University of Zurich

ZORA URL: https://doi.org/10.5167/uzh-67053

Journal Article

Originally published at:

Nüesch, Stephan (2012). Are multinational teams more successful? International Journal of Human Resource Management:3105-3113.

DOI: https://doi.org/10.1080/09585192.2011.610948 


\title{
Are multinational teams more successful?
}

\author{
Hartmut Haas $^{\mathrm{a}}$, Stephan Nüesch ${ }^{\mathrm{b} *}$ \\ ${ }^{a}$ Towers Watson, Executive Compensation, Eschersheimer Landstrasse 50, 60322 Frankfurt am \\ Main, Germany, Phone: +49 (0) 691505 5141, Fax: +49 (0) 691505 5140; \\ ${ }^{b}$ Department of Business Administration, University of Zurich, Plattenstrasse 14, 8032 Zürich, \\ Switzerland, Phone: +41 (0)44 63429 14, Fax: +41 (0)44 6344348.
}

Teams have become increasingly multinational in many sectors. The impact of national diversity on team performance is controversial, however. On the one hand, multinational teams may have access to a greater variety of task-relevant expertise, which should increase team performance. On the other hand, national diversity may complicate team collaboration and increase team conflict. Applying panel econometrics to 4,284 team observations in a globalized sector, we find evidence that multinational teams perform worse than teams with less national diversity.

Keywords: Controlled field environment, multinational teams, national diversity; professional sports; professional sports; team performance.

*Corresponding author: Email: stephan.nuesch@business.uzh.ch. 


\section{Introduction}

Teams have become increasingly important to organizations. Crown (2000) considers the rise of teams in organizations as both dramatic and comprehensive. In combination with the apparent globalization trend in the last decades, more and more teams have individuals coming from different countries and having different cultural backgrounds (Earley and Gibson 2002). It is, therefore, not surprising that the subject of national diversity management enjoys high popularity in practice (Rowley and Warner 2007; Sippola and Smale 2007). The question whether teams actually benefit from having a multinational team composition or not is contentious. The positive "value-in-diversity" perspective argues that firms may benefit from national diversity within the workforce because some relevant skills and knowledge sets might be nation specific (Lazear 1999a). Members from other nationalities may bring different but important ideas, expertise and know-how into the team. The negative perspective on multinational teams, however, states that combining workers of various different nationalities may hamper cooperation and collaboration due to the different languages and cultural backgrounds (Williams and O'Reilly 1998).

Whereas numerous empirical studies exist that analyze racial diversity (e.g., Hamilton et al. 2004, Jehn and Bezrukova 2004; McLeod et al. 1996; Mayo et al. 1996; Singh 2007; Timmerman 2000), the aspect of national diversity is, despite its practical importance, comparably understudied. The question whether multinational teams outperform or underperform compared to teams with less national diversity has been addressed for student teams solving business cases (Watson et al. 1993; Earley and Mosakowski 2000; Dahlin et al. 2005), virtual design teams (Gibson and Gibbs 2006), soccer teams (Andresen and Altmann 2006; Brandes et al. 2009; Nüesch 2009), and ice hockey teams (Kahane et al. 2009). The results of the related 
empirical studies are, however, conflicting and/or inconclusive. All in all, we know surprisingly little about the performance effects of national diversity among co-workers.

This paper aims to readdress the effect of national diversity on team performance by using a unique panel data set that offers four distinct advantages. First, by analyzing team composition and performance data for all games played in the Bundesliga, the highest German soccer league, during seven consecutive seasons (1999/00 until 2005/06), in total 4,284 team observations, no other empirical diversity study is based on such a large data sample. Second, German soccer teams are - unlike most student teams for example - truly global. Players from almost 50 different nationalities play in the Bundesliga. Whereas some teams are very heterogeneous incorporating players from multiple different nationalities, other teams have a great majority of German players. Blau's index of national diversity varies between 0 and 0.92 in our sample, covering almost the full possible range from 0 to nearly 1 . Third, doing research using sports data imitates laboratory research, as hypotheses can be tested in a controlled field environment (Kahn 2000; Wolfe et al. 2005). In professional team sports, all teams are governed by standardized rules of competition that eliminate factors that would otherwise substantially increase complexity and reduce the power of this study. Every team has to play with the same number of players (team size) and tries to win as many games as possible (objective). Games have the same duration and have the same underlying rules. Fourth, unlike other kinds of diversity research that rely on indirect performance indicators or subjective ratings by team members or their supervisors, team performance in professional team sports is identified by independent referees according to the rules of the game, leading to a more accurate and objective assessment of team effectiveness. In summary, we believe that game-level data of German soccer teams offers great quasi-laboratory conditions for testing the national diversity-performance relationship. 


\section{Theoretical Background}

This paper investigates the performance effects of national diversity in teams. In doing so, we define a player's nationality by his political citizenship. Based on theory, we outline two contrasting hypotheses about the influence of national diversity on team performance.

\section{The positive view on multinational teams}

Scholars with a positive perspective on multinational teams argue that national diversity increases team performance because multinational teams have access to a greater variety of task-relevant knowledge and expertise. The positive view builds on information and decision-making theory (Gruenfeld et al. 1996) and considers a team member's nationality as a task-relevant attribute that represents helpful informational diversity (Williams and O'Reilly 1998). Ayub and Jehn (2006, p. 186) state accordingly:

"[...] individuals from different nationalities bring a variety of information and ideas as they come from different social networks and social and educational backgrounds. Members with different national backgrounds are likely to have different perspectives, skills, information and knowledge bases, and talents."

The benefit of national diversity is linked to the attributed variety of skills of the different nationalities. If certain skills and knowledge are both national specific and relevant for team production, national diversity is especially important (Lazear 1999a).

The empirical study of Watson et al. (1993) show that project teams with high national diversity indeed outperform homogenous teams in the long run when it comes to the range of perspectives and alternatives generated. Dahlin et al. (2005) find evidence that most teams are located at the increasing part of the curvilinear U-shaped function between national diversity and the range, depth, and integration of information use of student teams solving a business case. 
Andresen and Altman (2006) find a positive correlation between the national diversity of soccer teams and their sportive success. However, they do not control for unobserved team heterogeneity that is likely to confound the results as Brandes et al. (2009) and Nüesch (2009) show. In line with the positive perspective on multinational teams we conjecture:

\section{H1: National diversity increases team performance, ceteris paribus.}

\section{The negative view on multinational teams}

The negative view of multinational teams considers a team member's nationality as a less jobrelated but more relational attribute that complicates mutual interaction and cooperation. This negative diversity perspective typically builds on the social identity theory (Tajfel and Turner 1979) and the similarity/attraction theory (Byrne 1971). High national diversity and team members' identification with their nationality can easily lead to social categorization processes, in which individuals from different nations make "in-group/out-group" distinctions (Gibson and Gibbs 2006). Stereotyping clearly accompanies these processes. As a result, several sub-groups emerge within a team along nationalities providing members with their own strong social identities. This development is detrimental to team performance. Conflicts may occur between members of different sub-groups and thereby hinder cooperation and decision-making processes in the main group, thus causing the negative effects of diversity on team output (Ayub and Jehn 2006).

Another theory that emphasizes a potential negative effect of multinational teams is the similarity-attraction-paradigm of Byrne (1971). It is based on the assumption that an impression of mutual attraction is established if two persons share the same or similar deep- and/or surfacelevel characteristics. Mutual attraction facilitates important communication and team integration 
processes in a second step. Accordingly, dissimilarity leads to less positive team integration and communication processes, which decreases team effectiveness. The explanations of the similarity-attraction-theory are in line with self-categorization and social identity theory and suggest a negative impact of national diversity on team performance.

The empirical study of Gibson and Gibbs (2006) shows that virtual teams with high national diversity score lower in innovation than more ethnocentric virtual teams. Kearney et al. (2009) find a negative relationship between national diversity and the team leader's rating about the team performance using data of 83 teams from eight different organizations. Kahane et al. (2009) show that teams from the National Hockey League (NHL) with foreign players from one European country attain a higher winning percentage than teams with players from different countries. In line with this negative diversity perspective we conjecture a second, alternative hypothesis:

H2: National diversity decreases team performance, ceteris paribus.

\section{Empirical Study}

\section{Study context}

This study tests the effects of national diversity on team performance using game-level information on team composition and team performance in the German Bundesliga. Professional team sports offer an empirical setting in which influential context factors are either constant for all team observations or can easily be controlled for by team fixed effects. Due to the frequency and regularity of athletic events, information on both team composition and performance is 
available in longitudinal format and large scale. Thus, the risk of omitted variable bias due to missing contextual information is low. In addition, soccer is a highly interactive game whose outcome depends on the complementary skills and the cooperation of all players on the field (attackers, midfielders, defenders and the goalkeeper). Thus, team composition including team diversity is critical in professional soccer (Franck and Nüesch 2010).

With 18 teams playing each other twice during a season, the full season includes 306 games, generating 612 team performance observations. Since the dataset covers seven seasons, the final sample consists of 4,284 team observations in 2,142 games. Unlike with US leagues, which are generally 'hermetic', the composition of European soccer leagues changes annually through promotion and relegation. The best three teams from the second division are promoted to the first division, while the weakest three in the latter are relegated to the second division. 26 different teams were present in the league in at least one of the seven observed seasons. The historical data on game results and game-specific team compositions were gathered from the kicker-Sportmagazin, a leading German soccer magazine.

Professional German soccer is big business. In the 2005/06 season the Bundesliga generated an estimated turnover of EUR 1.4 billion. At the same time, average game attendance increased to 40,600. No soccer league in Europe attracts more fans at the gate than the German Bundesliga (Jones 2007).

\section{Dependent variables}

To test the impact of national diversity on team performance we employ three different measures of team performance. The variable points measures the number of points that a team receives based on the game's outcome. For a victory, 3 points are awarded, for a tie 1 point is awarded, and a loss results in 0 points. As a second team performance indicator we use the goal difference 
between the two teams on the field. In case of a victory, goal difference is positive, whereas in case of a loss, the value is negative. Accordingly, a tied game results in a neutral score of zero for both teams. For the final placement in the league, both the number of points and the goal difference can be of relevance. If two teams have the same amount of points, the overall goal difference determines which team claims the upper ranking place. Besides these objective measures of game-specific team performance, we also use expert evaluation as a third, more subjective outcome variable. In German soccer, every game performance of a player who plays more than half an hour is individually and consistently evaluated and rated by sports experts using the German grading scale that varies between 1.0 (excellent) and 6.0 (very bad). The individual game evaluations are published by the highly respected kicker-Sportmagazin. For ease of interpretation, we transformed the original grades by subtracting the original grade from 7 . Team performance is then defined as the average of all game grades the fielded players receive. A Cronbach's Alpha of 0.84 indicates high reliability and internal consistency for the three performance measures.

\section{National diversity as explanatory variable}

In order to calculate game-specific diversity measures, we built a large dataset containing all individual game appearances in the German Bundesliga over seven seasons (58,772 observations in total) and each player's nationality(s). Players with two citizenships, e.g., German and Turkish, are treated as extra category, i.e., German-Turkish. National diversity was calculated according to Blau (1977) for every game of a team. Blau's index of heterogeneity is the formula most frequently referred to in measuring the diversity of categorical variables such as nationality. It is defined by 


$$
H=1-\sum_{i=1}^{n} p_{i}^{2}
$$

where $p$ is the proportion of group members in a category and $i$ is the number of different categories represented in the team (Blau 1977). If a fielded team consists of German players only, Blau's index is 0 . If each of the players on the field has a different nationality, Blau's index is nearly 1 , namely (n-1)/n. In our sample, Blau's index of national diversity varies between 0 and 0.92. The sample therefore fulfills the criteria proposed by Harrison and Klein (2007) concerning range and variability of diversity variables. Substantial range and variability are necessary for adequate hypotheses tests.

\section{Control variables}

In order to account for the possibility that location may influence a game's result and the composition of the fielded team, a dichotomous variable home game is incorporated. Carmichael and Thomas (2005) show that home field factors related to crowd and familiarity effects may influence the effectiveness of home and away team performances.

Not only different levels of national diversity influence team performance but also other factors such as the team's financial resources, coaching quality, human resource practices, infrastructure, or team spirit. A lot of these aspects are unobservable but constant over a season. As we employ game-specific data, we are able to control for all unobserved team heterogeneity that remains constant during a season by including seasonal team fixed effects. As less than $10 \%$ of the players change teams within an ongoing season, the composition of the entire team, from which a varying selection of players is elected to play in the competition games, remains more or less stable during a season. By including seasonal team fixed effects, we take into account that relevant and unobserved team characteristics may change considerably between seasons. A team 
that qualified for the UEFA Champions League in the preceding season, for example, generated substantial extra income with which the team could hire expensive but talented star players from all over the world. Simple correlations between game success and the national diversity of the fielded team may therefore be misleading. It is important to note that we identify the effect of national diversity by relating within-season team performance variation to within-season variation of national diversity. Due to injuries, sickness, suspensions of players, and varying playing strategies of the coach, the game-specific national diversity variable provides sufficient variation even within the same seasonal team.

To take account of unobserved aspects of the opposition team that may affect the game outcome (e.g., average playing quality of the players), we also include 126 dummies denoting the opposition team in a given season. Finally, seasonal dummies are used to control for interseasonal time effects.

\section{Analysis}

The hypotheses are tested using least squares methods, assuming that the differences between the categories of the dependent variables have a cardinal meaning. We use ordinary least squares (OLS) rather than ordered probit and ordered logit as estimation approach due to the incidental parameters problem of fixed effects in non-linear models. Unlike in the linear case, the non-linear ordered probit and logit models do not estimate consistent coefficients with fixed effects and limited time periods (Verbeek 2008). To account for non-independence of observations within the same game, we compute White-robust standard errors, clustered on games. To examine potential non-linear diversity effects, we also calculated the results when including a squared term of national diversity. However, we did not find evidence for a curvilinear relationship 
between national diversity and team performance, as the effect of the squared term was not statistically significant. This is true for all three specifications.

\section{Results}

As national diversity is measured on a scale that is difficult to interpret, Table 1 illustrates the standardized Beta coefficients and the p-values. The standardized Beta coefficients indicate the change in the dependent variable if the explanatory variable varies by one standard deviation. pvalues show the levels of statistical significance of the effects. The results in Table 1 indicate that national diversity has a negative effect on team performance in models on points (Beta $=-0.061$, $\mathrm{p}=0.030)$, goal difference $(\mathrm{Beta}=-0.051, p=0.080)$ and expert evaluation $($ Beta $=-0.055, p=$ 0.060). Thus, Hypothesis 2 stating that national diversity decreases team performance is supported. The magnitude of the national diversity effect is lower than the strong positive influence of playing at home. The Beta coefficients of the Home game dummy vary between 0.195 and 0.279 . Still, the negative effect of national diversity is statistically significant at the $5 \%$ level when using points as dependent variable and weakly statistically significant at the $10 \%$ level in the models explaining goal difference and expert evaluation using two-tailed test of statistical significance. As the variance of OLS estimates is lower in large samples, p-values between 0.030 and 0.080 do not seem great given the sample size of 4,284 observations. However, the variance of OLS estimates increases with the number of explanatory variables (261 in our case) due to multicollinearity. Given that the cases-to-variables ratio in our models is with 16.4 not much higher than the minimum threshold level of 10 suggested by Tabachnick and Fidell (2001) for social sciences, we consider the common levels of statistical significance $(10 \%$, $5 \%$, and $1 \%$ ) as appropriate. 
Table 1: OLS estimation results

\begin{tabular}{lrrrrrr}
\hline & \multicolumn{2}{c}{ Polnts } & \multicolumn{2}{c}{ Coal difierence } & \multicolumn{2}{c}{ Expert evaluation } \\
& Beta & $p$-value & Beta & $p$-value & Beta & $p$-value \\
\hline National diversity & -0.061 & 0.030 & -0.051 & 0.080 & -0.055 & 0.060 \\
Home game & 0.259 & 0.000 & 0.279 & 0.000 & 0.195 & 0.000 \\
Team seasonal fixed effects & yes & yes & & yes \\
Opposition team seasonal fixed effects & yes & yes & yes \\
Seasonal fixed effects & yes & yes & yes \\
R $^{2}$ & 0.221 & 0.265 & \multicolumn{2}{c}{0.201} \\
Observations & 4,284 & 4,284 & 4,284 \\
\hline
\end{tabular}

Notes: Ordinary Least Squares (OLS) estimation with White robust standard errors clustered on games. Standardized Beta coefficients and p-values according to two-tailed tests of statistical significance are shown.

\section{Discussion}

While the relationship between racial diversity and team performance can draw on a substantial body of research, this paper adds to the relatively new field of national diversity. In addition, this investigation contributes to the diversity literature by testing the effects of national diversity in a field environment in which accurate performance measures are easily available and in which contextual factors either are the same for all teams or can be held constant by using panel econometrics. Employing game-level data from the German Bundesliga, we find evidence for a negative relationship between national diversity and team performance. Homogenous teams are more likely to win a game than multinational teams, controlling for unobservable team heterogeneity. As soccer is a very interactive game, team success typically depends on the continuous cooperation of all fielded players. National diversity seems to complicate team interaction and collaboration. Language is usually one of the main channels through which national diversity affects team performance. Lazear (1999b) shows that speaking a common language facilitates social interactions. In the context of this study, however, language may play a 
secondary role, because team task in professional soccer requires little verbal communication. The found negative relation between national diversity and team performance is, therefore, even more surprising and hints at other factors relating to nationality, such as e.g., cultural differences in playing styles.

\section{Limitations}

Before discussing the potential managerial implications of the results, we wish first to acknowledge the limitations of our study. Even though we have clear information on a player's nationality, we do not know where the players have grown up, which religion they belong to, or which languages they speak. Our measure of national diversity may be associated with other unobserved but still relevant dimensions, like cultural values, religion, or still language. Thus, it is possible that parts of the effect we attributed to national diversity were actually due to unmeasured constructs. Further research should inquire into more detailed data on the cultural background of the workers to allow a more thorough understanding of how different aspects of diversity impact group effectiveness.

In addition, we only analyze a single-attribute heterogeneity index and do not examine the effects of group member characteristics in combination, as proposed by the faultine model of Lau and Murnighan (1998) and illustrated by Thatcher et al. (2003). Future research should explore both aligned and non-aligned effects of multiple diversity measures.

\section{Implications for managerial practice}

The same properties that make the sports context an advantageous area of research - accurate performance measures, controlled environment - also limit the generalizability of the results (Harder 1992). While the controlled field environment in professional sports allows high internal 
validity, it enforces the concern about external validity. External validity holds if the principle of induction holds, which means that behavioral regularities prevail in new situations as long as the relevant conditions remain substantially unchanged (Falk and Fehr 2003). Thus, it is not a question of yes or no, but rather one of whether business environments offer conditions similar to what professional soccer offers. Crown (2000) considers soccer teams as accurate representations of performance-oriented work groups that are expected to produce the primary product of an organization. Unlike research and development teams, production teams are characterized by exploitation rather than exploration using the typology of March (1991). Compared to project teams, production teams spend more time on issues of coordination and less time on strategy formulation and innovation. In professional soccer, innovation is restricted to the development of new playing strategies and tactics, but the general rules and objectives of the game are given (Wolfe et al. 2005). Hence, this special team type has to be kept in mind when applying the results. Whenever the team task is somehow blurry and team effectiveness is no longer confined to exploitation alone, national diversity is likely to have a less negative or even a positive impact on team performance. Whenever the team task is clearly defined, however, this study suggests that performance-oriented work teams should have low national diversity in order to maximize team effectiveness. This finding has clear implications for the human resource department when hiring new employees and forming teams.

\section{Acknowledgements}

We are grateful to Agnes Bäker, Ed Lazear, an anonymous referee and to the seminar participants at the University of Zürich for helpful comments. An earlier version of this paper was also presented at the 2009 Meeting of the Academy of Management in Chicago, USA. 


\section{References}

Andresen, M., and Altmann, T. (2006), 'Diversity und Erfolg im Profi Fußball,' [Diversity and Success in Professional Soccer], Zeitschrift für Führung und Organisation, 75, 325-332.

Ayub, N., and Jehn, K. A. (2006), 'National diversity and conflict in multinational workgroups. The moderating effect of nationalism,' International Journal of Conflict Management, 17: $181-202$.

Blau, P. M. (1977), Inequality and heterogeneity - A primitive theory of social structure, New York - London: The Free Press.

Brandes, L., Franck, E., and Theiler, P. (2009), 'The Effect from National Diversity on Team Production - Empirical Evidence from the Sports Industry,' Schmalenbach Business Review, 61, 225-246.

Byrne, D. (1971), The Attraction Paradigm, New York/London: Academic Press.

Carmichael, F., Thomas, D., and Ward, R. (2000), 'Team performance: The case of English Premiership Football,' Managerial and Decision Economics, 21(1): 31-45.

Crown, D. F. (2000), 'Building multidimensional, context-relevant categorization heuristic for organizational work teams: the tos-tab typology,' Research in Personnel and Human Resources Management, 18: 93-136.

Dahlin, K. B., Weingart, L. R., and Hinds, P. J. (2005), ‘Team diversity and information use,' Academy of Management Journal, 48(6), 1107-1123.

Earley, P. C. and Mosakowski, E. (2000), 'Creating hybrid team cultures: an empirical test of transnational team functioning,' Academy of Management Journal, 43(1): 26-49.

Earley, P. and Gibson, C. B. (2002), Multinational work teams: A new perspective, Mahway, NJ: Erlbaum. 
Falk, A., and Fehr, E. (2003), 'Why labour market experiments?,' Labour Economics, 10: 399406.

Franck, E., and Nüesch, S. (2010), 'The effect of talent disparity on team productivity in soccer,' Journal of Economic Psychology, 31: 218-229.

Gruenfeld, D. H., Mannix, E., Williams, K. Y., and Neale, M. A. (1996), 'Group composition and decision making: How member familiarity and information distribution affect process and performance,' Organizational Behavior and Human Decision Processes, 67(1): 1-15.

Gibson, C. B. and Gibbs, J. L. (2006), 'Unpacking the concept of virtuality: The effects of geographic dispersion, electronic dependence, dynamic structure, and national diversity on team innovation,' Administrative Science Quarterly, 51, 451-495.

Harder, J. W. (1992), 'Play for pay: effects of inequity in a pay-for-performance context,' Administrative Science Quarterly, 37: 321-335.

Harrison, D. A. and Klein, K. J. (2007), 'What's the difference? Diversity constructs as separation, variety, or disparity in organizations,' Academy of Management Journal, 32(4): 1199-1228.

Jehn, K. A., and Bezrukova, K. (2004), ‘A field study of group diversity, workgroup context, and performance,' Journal of Organizational Behavior, 25(6): 703-729.

Jones, D. (2007), Annual Review of Football Finance, Düsseldorf: Deloitte.

Kahn, M. L. (2000), 'The sports business as a labor market laboratory,' Journal of Economic Perspectives, 14: 75-94.

Kearney, E., Gebert, D., and Voelpel, S. C. (2009), 'When and how diversity benefits teams: The importance of team members' need for cognition,' Academy of Management Journal, 52, (3), 581-598. 
Lau, D. C., and Murnighan, J. K. (1998), 'Demographic diversity and faultlines: The compositional dynamics of organizational groups,' Academy of Management Review, 23(2): $325-340$.

Lazear, E. P. (1999a), 'Globalization and the market for team-mates,' The Economic Journal, 109(454): 15-40.

Lazear, E. P. (1999b), 'Language and Culture,' Journal of Political Economy, 107(6), S95-S126.

March, J. G. (1991), 'Exploration and exploitation in organizational learning,' Organization Science, 2(1): 71-87.

McLeod, P. L., Lobel, S. A., and Cox, T. H. J. (1996), 'Ethnic diversity and creativity in small groups,' Small Group Research, 27: 248-264.

Mayo, M., Pastor, J. C., and Meindl, J. R. (1996), 'The effects of group heterogeneity on the selfperceived efficacy of group leaders,' The Leadership Quarterly, 7(2): 265-284.

Nüesch, S. (2009), 'Are demographic diversity effects spurious?,' Economic Analysis \& Policy, 39: 379-388.

Rowley, C. and Warner, M. (2007), 'Introduction: globalization international human resource management,' International Journal of Human Resource Management, 18: 703-716.

Singh, V. (2007), 'Ethnic diversity on top corporate boards: a resource dependency perspective,' International Journal of Human Resource Management, 18: 2128-2146.

Sippola, A., and Smale, A. (2007), 'The global integration of diversity management: a longitudinal case study,' International Journal of Human Resource Management, 18: 1895-1916.

Tabachnick, B. G. and Fidell, L. S. (2001). Using Multivariate Statistics. Boston: Allyn \& Bacon. 
Tajfel, H., and Turner, J. C. (1979), 'An integrative theory of intergroup conflict,' In S. Worchel, and W. G. Austin (Eds.), The social psychology of intergroup relations: 94-109. Monterey, CA: Brooks-Cole.

Thatcher, S. M. B., Jehn, K. A., and Zanutto, E. (2003), 'Cracks in diversity research: The effects of diversity faultlines on conflict and performance,' Group Decision \& Negotiation, 12(3): 217-241.

Timmerman, T. A. (2000), 'Racial diversity, age diversity, interdependence, and team performance,' Small Group Research, 31(5): 592-606.

Verbeek, M. (2008). A Guide to Modern Econometrics. West Sussex: John Wiley \& Sons.

Watson, W. E., Kumar, K., and Michaelsen, L. K. (1993), 'Cultural diversity's impact on interaction process and performance: comparing homogeneous and diverse task groups,' Academy of Management Journal, 36(3): 590-602.

Williams, K. Y., and O'Reilly, C. A. (1998), 'Demography and diversity in organizations: A review of 40 years of research,' in B. M. Staw, and R. M. Sutton (Eds.), Research in Organizational Behavior, Vol. 20: 77-140. Stamford, CT: JAI Press.

Wolfe, R. A., Weick, K. E., Usher, J. M., Terborg, J. R., Poppo, L., Murrell, A. J., Dukerich, J. M., Core, D. D., Dickson, K. E., and Jourdan, J. S. (2005), ‘Sport and organizational studies. Exploring synergy,' Journal of Management Inquiry, 14: 182-210. 